\title{
Historical comparison of the 2001/2002 drought in the Canadian Prairies
}

\author{
B. Bonsal*, M. Regier \\ Environment Canada, 11 Innovation Boulevard, Saskatoon, Saskatchewan S7N 3H5, Canada
}

\begin{abstract}
Over the west-central Canadian Prairies, precipitation was well below normal for a remarkable 8 consecutive seasons from September 2000 through August 2002. The precipitation deficits were associated with severe agricultural, hydrologic, and socio-economic impacts over much of the area. This study compares the spatial extent and severity of the 2001/2002 Canadian Prairie drought to previous droughts during the period of instrumental records. The Standardized Precipitation Index (SPI) and Palmer Drought Severity Index (PDSI) show that the worst and most prolonged Prairie-wide droughts during the period 1915-2002 occurred in the early part of the 20th century. Over the agricultural region of the Prairies, 2001 and 2002 generally ranked high in terms of spatial extent and severity of drought; at some stations the 2001/2002 drought was the most severe one on record. More importantly, it followed a prolonged lack of dry years, and this likely contributed to the severity of its impacts. Results from this study are an initial step toward the quantification and better understanding of both past and future drought occurrence over interior regions of North America.
\end{abstract}

KEY WORDS: Drought $\cdot$ Canadian Prairies $\cdot$ Standardized Precipitation Index $\cdot$ SPI $\cdot$ Palmer Drought Severity Index $\cdot$ PDSI · Climate change

\section{INTRODUCTION}

Since most human activities, as well as ecosystem health, depend on an adequate supply of water, droughts pose a serious threat to society and the environment. Prolonged widespread drought has adverse effects on agriculture, industry, municipalities, recreation, and aquatic ecosystems, because it depletes soil moisture, reduces stream flow, and lowers lake, reservoir and groundwater levels. This affects numerous economic activities, e.g. by decreased agricultural production and hydroelectric power generation, and increased freshwater transportation costs. Drought also causes environmental damage such as reduced water quality, wetland loss, soil erosion and degradation, and habitat destruction. In light of the economic and environmental significance of drought, scientific concern has been expressed regarding impacts of climate change on future drought frequency, duration, and severity in various regions of the globe (Arnell et al. 2001).
Simply stated, drought is a prolonged period of abnormally dry weather that depletes water resources for human and environmental needs (AES 1986). However, each drought is different, depending on factors such as area affected, duration, intensity, antecedent conditions, and the region's capability to adapt to water shortage. In general, the definition of drought depends on the user and the geographical region in question. For example, a meteorological drought often occurs when there is significantly below-normal precipitation over an extended period, frequently intensified by anomalously high temperatures that increase evapotranspiration. The degree of moisture shortage and the length of time it takes for a meteorological drought to develop varies from region to region (Maybank et al. 1995). Meteorological drought often leads to other types of drought, including agricultural (periods during which soil moisture is insufficient to support crops), hydrologic (prolonged periods of unusually low surface run-off and shallow groundwater levels), and 
socio-economic drought (an unusual shortage of water that produces an adverse effect on society and the economy) (Maybank et al. 1995).

Most areas of Canada periodically experience drought, but the agricultural regions of the Canadian Prairies (see Fig. 1) are more drought-prone, mainly due to their location in the lee of the Rocky Mountains, and their economy is more vulnerable due to its dependence on agriculture. In any given year, there is usually some region within the Prairies that has a precipitation deficiency, but it is the large area (Prairie-wide) droughts that have the greatest impacts (O'Brien 1994). Using a variety of drought indicators at various temporal scales, several studies have identified multiyear large-area droughts over the Canadian Prairies during the instrumental record: in the 1890s, 1910s, 1930s, 1960s, and 1980s (e.g. Phillips 1990, Chipanshi et al. 2006); while the worst 20th century agricultural droughts were in 1936-1937, 1961, 1984-1985 and 1988 (O'Brien 1994). Nkemdirim \& Weber (1999) used the Palmer Drought Severity Index (PDSI) to compare the southern Canadian Prairie droughts of the 1930s and the 1980s. They determined that although the area under mild drought was $16 \%$ larger in the 1930s as compared to the 1980s, the region impacted by extreme drought was larger in the 1980s. A paleoclimatic study by Sauchyn \& Skinner (2001) used treering chronologies to extend the drought record of the southwestern Canadian Plains back to 1597. They determined clusters of drought years occurring in the $1690 \mathrm{~s}, 1720 \mathrm{~s}, 1750 \mathrm{~s}-1760 \mathrm{~s}, 1790 \mathrm{~s}-1800 \mathrm{~s}, 1820 \mathrm{~s}$, and 1850s-1860s.

By several standards, 2001 and 2002 can be considered drought years over much of the Canadian Prairies, with consistently negative precipitation departures of $10 \%$ to $50 \%$ below normal over the entire region (Bonsal \& Wheaton 2005). During 2001, dry conditions were most severe in Alberta and western Saskatchewan, and they extended farther eastward into Manitoba in 2002. Well below normal precipitation persisted for every season from autumn 2000 through summer 2002, beginning in autumn 1999 in west-central Alberta. The 2001/2002 drought did not experience extreme positive temperature anomalies over the Prairies, however, with values only averaging around 0.5 to $1.0^{\circ} \mathrm{C}$ above normal. Furthermore, the highest positive temperature anomalies were observed during autumn and winter, while spring and summer were associated with small positive or even negative values. In terms of atmospheric circulation, the 2001/ 2002 drought was related to a northward extension of persistent drought producing circulation anomalies that impacted the continental USA. This differed from patterns associated with previous severe, multi-season Prairie droughts (e.g. 1961 and 1988) in that the circu- lation during 2001 and 2002 lacked the distinct meridional flow over the North Pacific and North America that has been associated with previous dry periods over western Canada (Bonsal \& Wheaton 2005).

Wheaton et al. (2005) documented and evaluated the climatology, potential causes, impacts, and adaptation strategies associated with the 2001/2002 Canadian drought with an emphasis on agricultural and water sectors. They determined that the persistence of dry weather had severe impacts, including almost complete agricultural crop production losses, land and pasture degradation, reduced or non-existent stream flows, decreased hydroelectric production, and significant increases in forest fires. Although similarities to other major drought episodes over the Canadian Prairies were noted, large-area climatological comparisons to the 2001/2002 episode were not extensively addressed.

The main objective of this study is to compare the spatial extent and severity of the 2001/2002 Canadian Prairie drought to previous droughts during the period of instrumental record. The analysis was carried out on a Prairie-wide basis using 2 different drought indicators, namely the PDSI and the Standardized Precipitation Index (SPI) at several temporal scales. This study compares the recent drought to past episodes, and also provides insight into future drought probability in the Prairies, given the prospect of climate change. The data and methodology are described in Section 2, while Section 3 presents historical comparisons of the 2001/2002 drought with previous droughts. The paper concludes with a summary and discussion in Section 4.

\section{DATA AND METHODOLOGY}

\subsection{Data}

Monthly mean temperature and precipitation data for climate stations within and in proximity to the Canadian Prairies were taken from the Adjusted Historical Canadian Climate Data set (available at: www.cccma.bc.ec.gc.ca./hccd/). These stations contain variable record lengths with earliest series for a few locations extending back to the 1890s, and most stations having values through 2002. For temperature, homogeneity problems caused by station relocation and changes to instrumentation and observing practices have been addressed using a regression model technique (Vincent 1998, Vincent \& Gullett 1999). Precipitation values were adjusted to account for gauge undercatch, wetting loss, and trace events (Mekis \& Hogg 1999).

The historical analysis of Prairie droughts requires climate stations with long enough series to include 
known droughts in the early 20th century, and sufficient density to provide adequate spatial coverage of the agricultural region of the Canadian Prairies. Taking these considerations into account, 21 stations for the agricultural years (September to August) of 1915 to 2002 were incorporated (Fig. 1). These locations were also chosen on the basis of relatively few missing values $(<5 \%$ for precipitation, and $<1 \%$ for temperature series). A study area approximating the agricultural growing region of the Canadian Prairies was identified, based on the 21-station network (shaded area in Fig. 1). Nearby stations outside the study area were chosen due to their close proximity to the identified study area and were used to facilitate the gridding procedure described in Section 2.3.

Drought analyses were initiated with data for 1915, based on station density and previously identified drought occurrences. A start period of 1900 or even 1910 provided too few stations to adequately represent the agricultural region. Although initiating the analysis in 1920 provided a few more locations than shown in
Fig. 1, this excluded severe droughts of the late 1910s (O'Brien 1994). Since it is desirable to have continuous PDSI and SPI monthly time series, missing temperature and precipitation values for the entire period were infilled using the 1971-2000 climatological normals for the month in question. This method has been previously used to calculate drought indices over regions of Canada and should not significantly affect the analyses, due to the infrequency of missing values at the identified 21 stations.

\subsection{Drought indices}

Although no universally accepted definition for drought exists, numerous indices have been incorporated to quantify its severity. Meteorological approaches range from indices that only consider precipitation (e.g. SPI), to more complex methods that incorporate a water balance approach using precipitation, potential evapotranspiration, antecedent

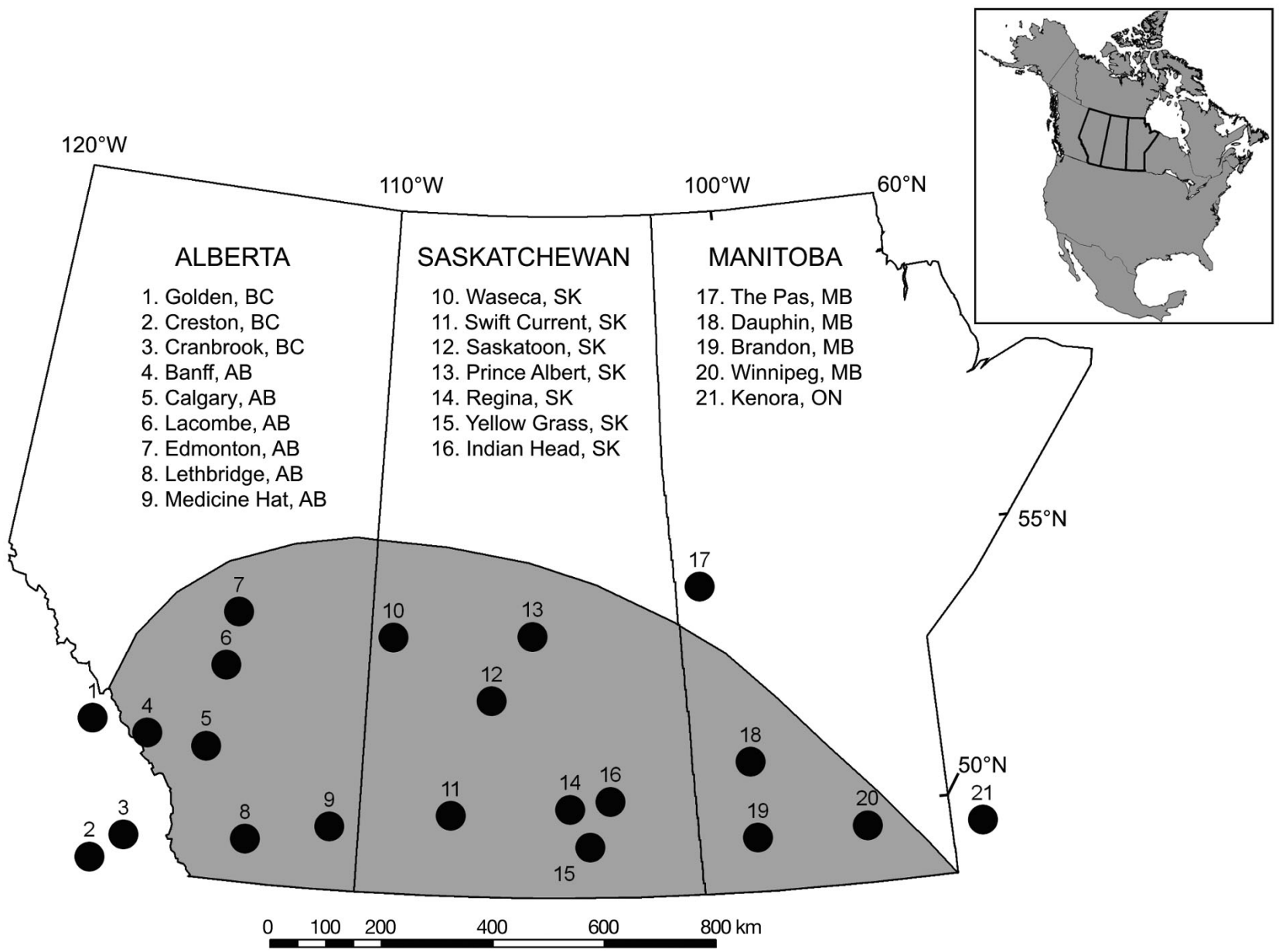

Fig. 1. Locations and names of climate stations used; shaded: Canadian Prairie study area. BC: British Columbia (Stations 1-3); ON: Ontario (Station 21) 
soil moisture, and runoff (e.g. PDSI). Agricultural drought indices relate to soil moisture availability and include for example, the Crop Moisture Index (Palmer 1968) and the Computed Soil Moisture Index. Hydrologic indicators such as the Surface Water Supply Index (Shafer \& Dezman 1982) and the Palmer Hydrological Drought Index generally use groundwater levels, stream flow, snow pack, and soil moisture as input variables. However, long-term (i.e. 20th century) values of these hydrologic-related variables (including soil moisture) are not available over the entire Prairie study area, and as a result, this investigation uses the SPI and PDSI. Both measures have been used to assess drought conditions over various regions of North America and have the advantage of only requiring monthly temperature and precipitation as input variables.

The PDSI indicates the physical severity of drought and is useful for longer-term (i.e. seasonal to annual) agricultural and hydrologic applications. Developed by Palmer (1965), it was intended to measure the cumulative departure of moisture supply from a water balance viewpoint. It has been used over North America for both monitoring drought (e.g. the Climate Prediction Center, Agriculture and Agri-Food Canada) and for making operational water management decisions. The calculation requires monthly precipitation and temperature, and the station's latitude for estimating evapotranspiration. Initially, a hydrologic accounting (by months) is carried out for a long series of years. The results are then summarized to obtain coefficients that depend on the station's climate. In this study, the entire period 1915-2002 was used to derive these coefficients for each station. The data series were then reanalyzed (using the derived coefficients) to determine the amount of moisture required for normal climate during each month. PDSI values typically range between +4 and -4 , negative values indicating a shortage of water (Guttman 1998, Keyantash \& Dracup 2002). Classifications of drought based on the PDSI are given in Table 1. Note that the calculated monthly PDSI value is comprised of only one-third of the current month's precipitation deficit and almost nine-tenths of the previous month's PDSI (Guttman 1998). Therefore, the PDSI for a given month contains a long-term memory of previous moisture conditions.

The SPI (McKee et al. 1993) is a meteorological drought index that interprets observed precipitation as a standardized departure with respect to a precipitation probability distribution function. Unlike PDSI, it can be computed over any duration. The first step is to determine a probability density function that describes the long-term (1915-2002) series of observations. McKee et al. (1993) suggested the 2-parameter gamma
Table 1. Moisture classifications based on the PDSI (Palmer 1965) and SPI (McKee et al. 1993)

\begin{tabular}{|llcc|}
\hline Classification & & PDSI & SPI \\
\hline Drought & Exceptional & $\leq-5.0$ & $\leq-2.5$ \\
& Extreme & $>-5.0$ to -4.0 & $>-2.5$ to -2.0 \\
& Severe & $>-4.0$ to -3.0 & $>-2.0$ to -1.5 \\
& Moderate & $>-3.0$ to -2.0 & $>-1.5$ to -1.0 \\
& Mild & $>-2.0$ to -1.0 & $>-1.0$ to -0.5 \\
Near normal & & $>-1.0$ to 1.0 & $>-0.5$ to 0.5 \\
Wet & & 1.0 to $<2.0$ & 0.5 to $<1.0$ \\
& Mild & 2.0 to $<3.0$ & 1.0 to $<1.5$ \\
& Moderate & 3.0 to $<4.0$ & 1.5 to $<2.0$ \\
& Severe & 4.0 to $<5.0$ & 2.0 to $<2.5$ \\
& Extreme & $\geq 5.0$ & $\geq 2.5$ \\
& Exceptional & $\geq 5$ & \\
\hline
\end{tabular}

density function, which is the same procedure incorporated in this analysis. Other functions, including Pearson Type III, have also been used (e.g. Guttman 1999). The cumulative probability of an observed precipitation amount (for the desired time period) is then computed based on the density function. The inverse normal (Gaussian) function is then applied to this probability resulting in an SPI value. The SPI is also a dimensionless value where negative values indicate drought (Guttman 1998, Heim 2002). Drought intensities based on various SPI classes are given in Table 1.

Some researchers have recently questioned the use of PDSI in studying drought, due to its complex structure, exceptionally long memory, and applicability across climatically diverse regions (e.g. Guttman 1998, Keyantash \& Dracup 2002). They recommend the SPI as a superior drought indicator, since it is easy to interpret and can be applied universally to any location at several different temporal scales. The use of both the PDSI and SPI approaches in our study allows for a comparison of 2 commonly used drought indices in their ability to characterize the severity and spatial extent of the 2001/2002 drought and its relationship to past drought occurrences over the Prairies. In addition, since the PDSI incorporates temperature in its calculation, it may be more applicable to identifying droughts that have been influenced by anomalously high temperatures.

\subsection{Methodology}

Droughts occur on a variety of temporal scales ranging from shorter agricultural droughts lasting months to seasons, to hydrologic droughts of one to several years, to mega-droughts lasting several years to decades. For comparisons of the 2001/2002 Canadian Prairie drought, this investigation focused on summer 
(June-July-August), 1 yr, and 2 yr durations. Since the 2001/2002 dry period was initiated as far back as 1998 in some regions of the Canadian Prairies (Wheaton et al. 2005), a 5 yr interval was also examined. The 1, 2, and 5 yr periods are based on the agricultural year defined as September through August. Therefore, 2002 refers to the period September 2001 to August 2002 and the 1915-2002 study period runs from September 1914 through August 2002. For PDSI, the derived monthly indices were averaged to obtain the summer, and 1,2, and 5 yr values.

One objective of this study was to quantify the severity and spatial extent of historical drought over the entire Canadian Prairie. Since the stations in Fig. 1 are not uniformly distributed within this region, the derived PDSI and SPI values from individual stations were spatially interpolated to a $50 \times 50 \mathrm{~km}$ grid using a cubic spline interpolation procedure resulting in 291 grids. The spatial extent of the 2001/2002 and other historical droughts were quantified by determining the area (percentage of grids) encompassed by the thresholds for severe drought (PDSI $\leq-3.0$; SPI $\leq-1.5$ ) and extreme drought $(\mathrm{PDSI} \leq-4.0$; $\mathrm{SPI} \leq$ -2.0 ), on a summer, and 1, 2, and $5 \mathrm{yr}$ basis. Average PDSI and SPI values for all grids were also calculated to quantify the severity of the drought. These parameters were then used to compare the 2001/2002 drought with other droughts in the study period and to determine its rank in terms of spatial extent and severity.

\section{RESULTS}

\subsection{Drought in $2001 / 2002$}

Figs. 2 \& 3 show SPI and PDSI values for various periods associated with the 2001/2002 drought. The 2 yr period of 2001/2002 (Fig. 2e) was associated with severe (SPI $\leq-1.5)$ and extreme (SPI $\leq-2.0)$ drought centered in the northern portions of the study region.
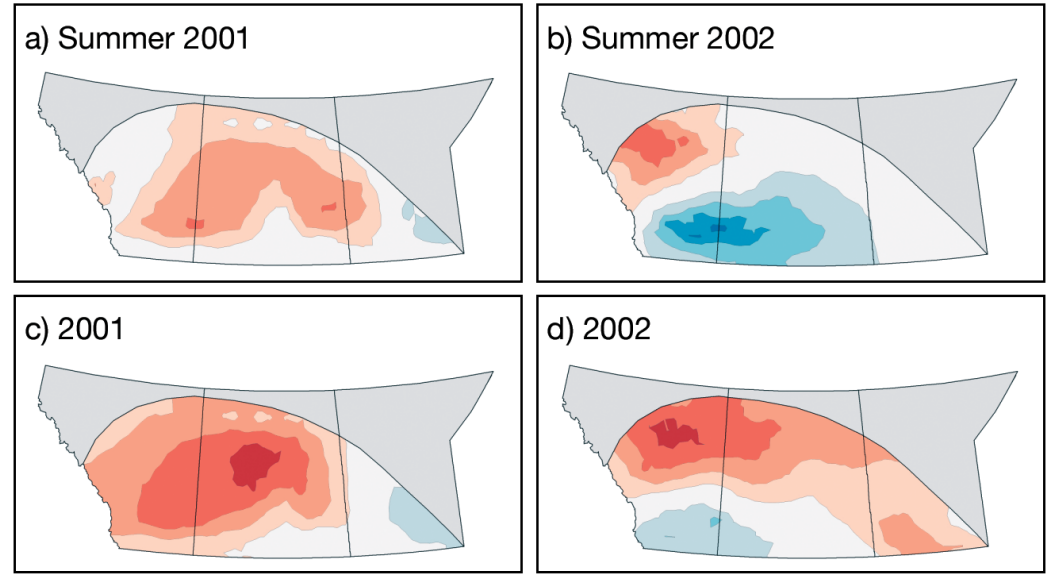

e) 2001-2002

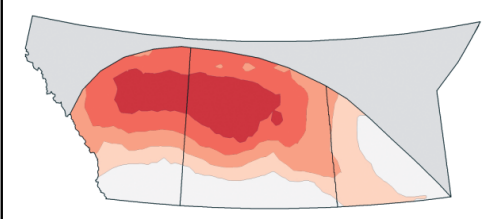

f) $1998-2002$
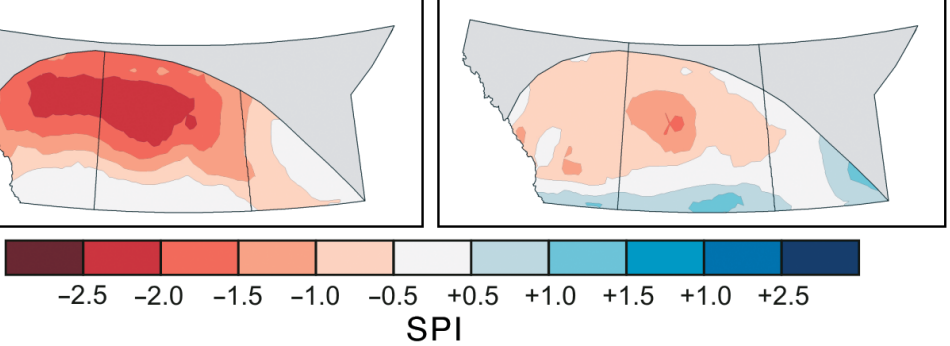

Fig. 2. Standardized Precipitation Index (SPI) for the 2001/2002 drought in the Canadian Prairies. Summer: June to August; years are agricultural year (September to August)
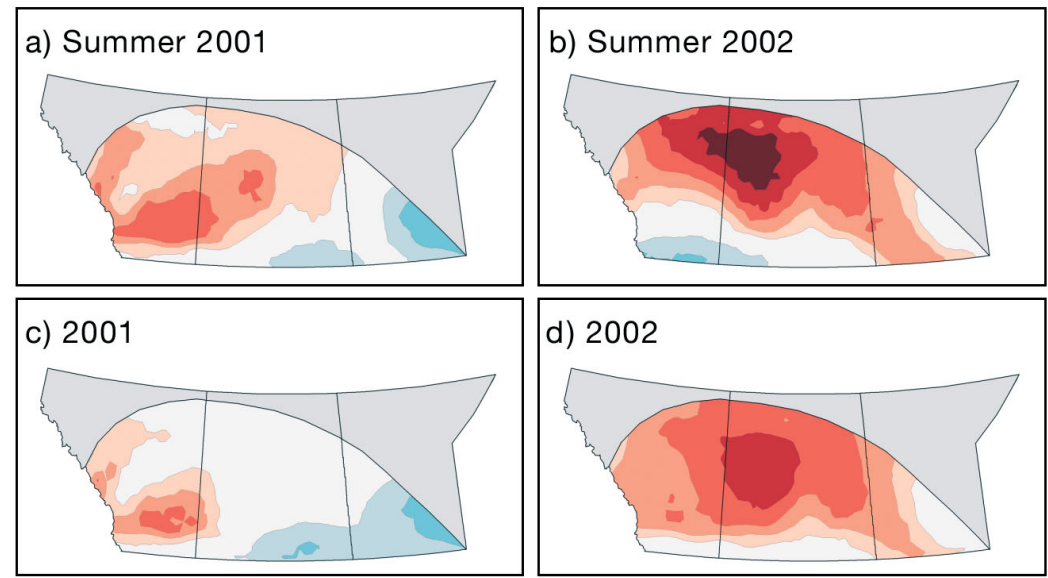

\section{d) 2002}
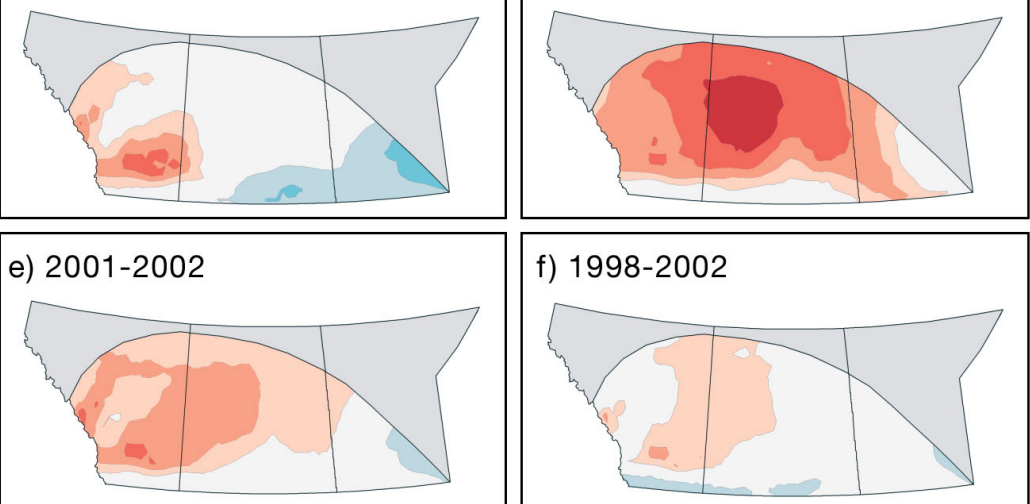

f) $1998-2002$

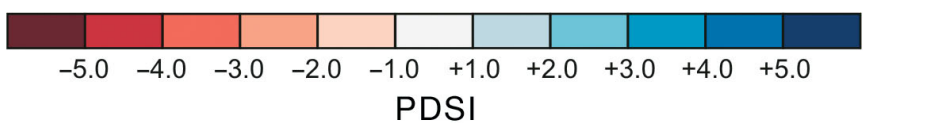

Fig. 3. Palmer Drought Severity Index (PDSI) for the same time periods as in Fig. 2 
The extreme south and most of Manitoba had near normal values. In 2001, the drought was concentrated in the central regions of Alberta and Saskatchewan (Fig. 2c). There was a pronounced northward shift of dry conditions in 2002, while the southwestern Prairies had wetter than normal conditions, especially during summer (Fig. 2b). Daily precipitation values for the climate stations in this area (not shown) reveals that 2 major early summer events on June 8-11 and June $16-19,2002$, accounted for $>90 \%$ of the entire summer's normal precipitation. For the most part, the rest of the summer was drier than normal in this area.

Although negative SPI occurred during the summers of 2001 and 2002 (Fig. 2a,b), the more extreme values for the 1 and 2 yr time intervals suggest persistent dry conditions for this entire period. This agrees with Bonsal \& Wheaton (2005), who found that well below normal precipitation was recorded for 8 consecutive seasons from autumn 2000 through summer 2002 in the west-central Prairies. The 5 yr SPI values in Fig. $2 \mathrm{f}$ reveal drier than normal conditions over the central Prairies (west-central Saskatchewan). However, there is virtually no area affected by severe drought.

The PDSI results in Fig. 3 show similar large-scale spatial patterns, but with the driest conditions in 2002. This is likely due to the PDSI containing a long-term memory of previous moisture conditions. As a result, the 2002 PDSI is determined by dry conditions during 2001 and 2002. The summer and 1 yr values of the 2002 PDSI show strongest drought conditions over the north-central Prairie region with severe (PDSI $\leq-3.0$ ) drought encompassing most of Saskatchewan and western Alberta. The 2 and 5 yr periods also had drier than normal conditions, but were not as severe, compared to the SPI.

\subsection{Historical comparison}

On a Prairie-wide basis, the spatial extent and severity of the 2001/2002 drought was exceeded on several occasions, particularly from 1915 through the mid1930s. For SPI, droughts in the early part of the record often covered a much larger area and were more severe than those of 2001 and 2002 (Figs. 4 \& 5, Table 2). Individual drought years in the 1960s and the 1980s (particularly, 1961 and 1988) also tended to equal or exceed the 2001/2002 drought. The year 1929 stands out with the most severe summer and $1 \mathrm{yr}$ drought, with an extraordinary $70 \%$ of the grids encompassed by severe drought $(50 \%$ by extreme drought) during summer, and even more grids encompassed for the agricultural year (Table 2). Average SPI values for the entire study area were near -2 . In comparison, the 1 yr values associated with 2001 ranked 5th and 7 th in percentage area covered by severe and extreme drought and 7 th in terms of average SPI (-1). The year 2002 ranked 12th, 10th, and 14th, respectively. The droughts of 2001 and 2002 were, however, the worst $1 \mathrm{yr}$ episodes since 1961. The $2 \mathrm{yr}$ period of 2001-2002 ranked even higher with $40 \%$ of the grids impacted by severe drought (5th rank), and $24.4 \%$ by extreme drought (near 1st rank), and 6th rank for average SPI. This was the most serious 2 yr drought since the mid-1930s. For summer, the years 2001 and 2002 did not rank highly in terms of drought spatial extent and severity, due to the wetter than normal conditions over the southwestern Prairies during the summer of 2002 (Fig. 2b). For the 5 yr interval, 1998 to 2002 ranked well below the dry periods of the 1920s and 1930s.

Overall findings for the PDSI correspond to those of the SPI in that the majority of the worst droughts occurred early in the record (Figs. $6 \&$;, Table 2). However, unlike SPI, 2002 ranked very high on a summer and 1 yr basis. In fact, it ranked 1st for 1 yr drought based on percentage area encompassed by severe drought, 3rd for extreme drought, and 2nd in terms of the average PDSI value; 2001 was less severe than 2002 (cf. Fig. 3). The years 1919 and 1988 ranked as the most severe summer droughts on the Prairies, while 1919, 1930, and 2002 were the most serious $1 \mathrm{yr}$ episodes. With the exception of 1988, 1989, and 2002, most other severe summer and $1 \mathrm{yr}$ droughts occurred early in the century, and the most severe 2 and $5 \mathrm{yr}$ period droughts were in the 1920s and 1930s.

Although some inter-decadal variability is observed, it is clear that the most serious and prolonged droughts occurred in the early part of the record (Figs. 6 \& 7). This trend is also apparent in the SPI, but is less pronounced. The SPI also tends to be associated with more inter-annual variability, which is likely the result of the influence of meteorological conditions during the current period of interest, while the PDSI has a long-term memory of previous moisture conditions.

Indications into the large-scale spatial variability of drought patterns within the region are provided in Figs. 8 \& 9 which show 1 yr SPI and PDSI values for selected severe droughts. In terms of SPI, the years 1929 and 1961 ranked as two of the worst drought years on record (Table 2) while 1919 and 1988 (which were also highly ranked) have been identified by other studies as being particularly severe Prairie drought years (O'Brien 1994, Bonsal \& Wheaton 2005). In 1929, there were severe to exceptional drought conditions over almost the entire Prairie region with driest conditions in Manitoba and the northern agricultural zone. The 1961 drought was also associated with negative SPI over most of the 

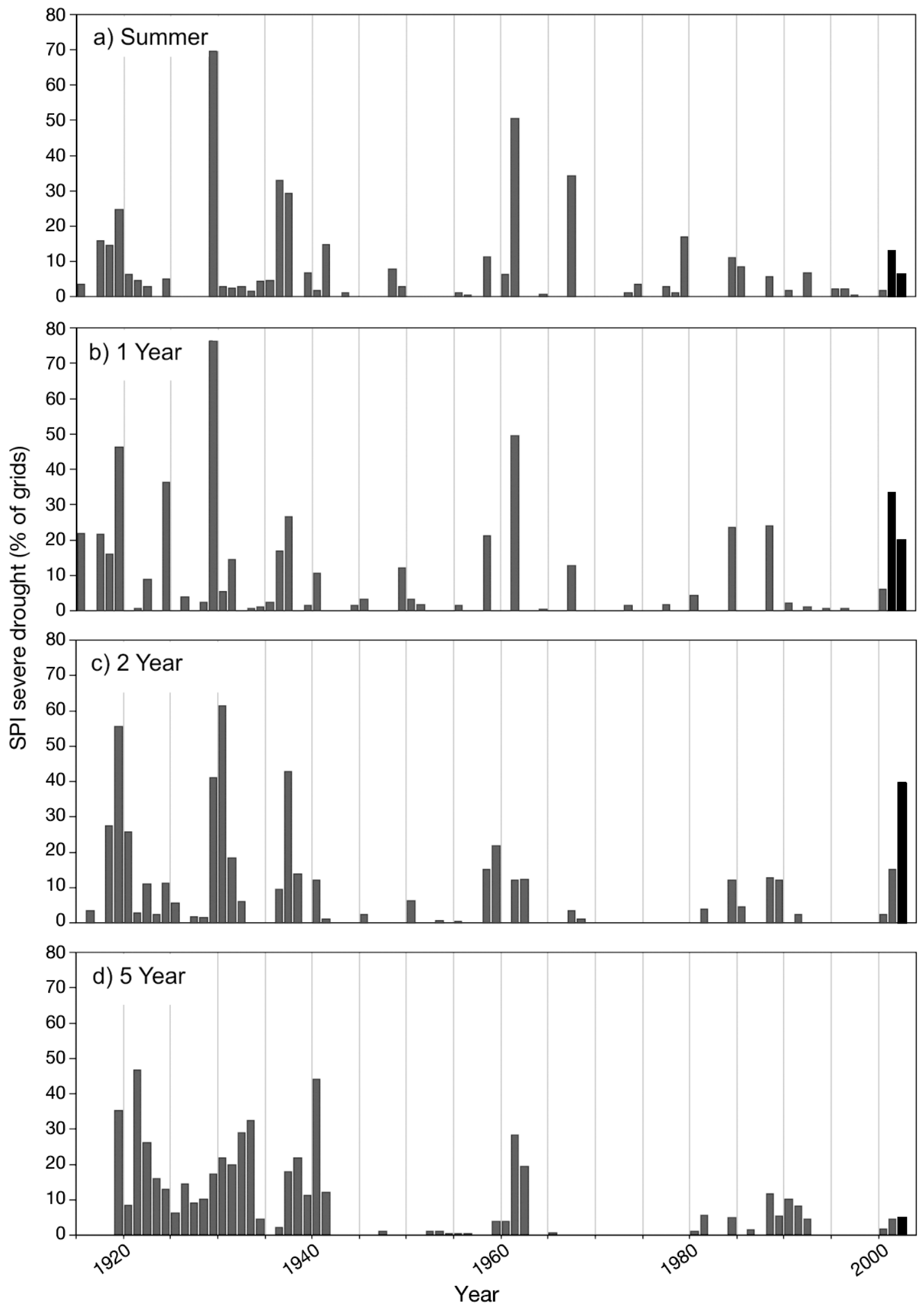

Fig. 4. Standardized Precipitation Index (SPI). Percentage of grids with severe drought (SPI $\leq-1.5)$ during 1915-2002. Values for the 2001/2002 drought are in black 

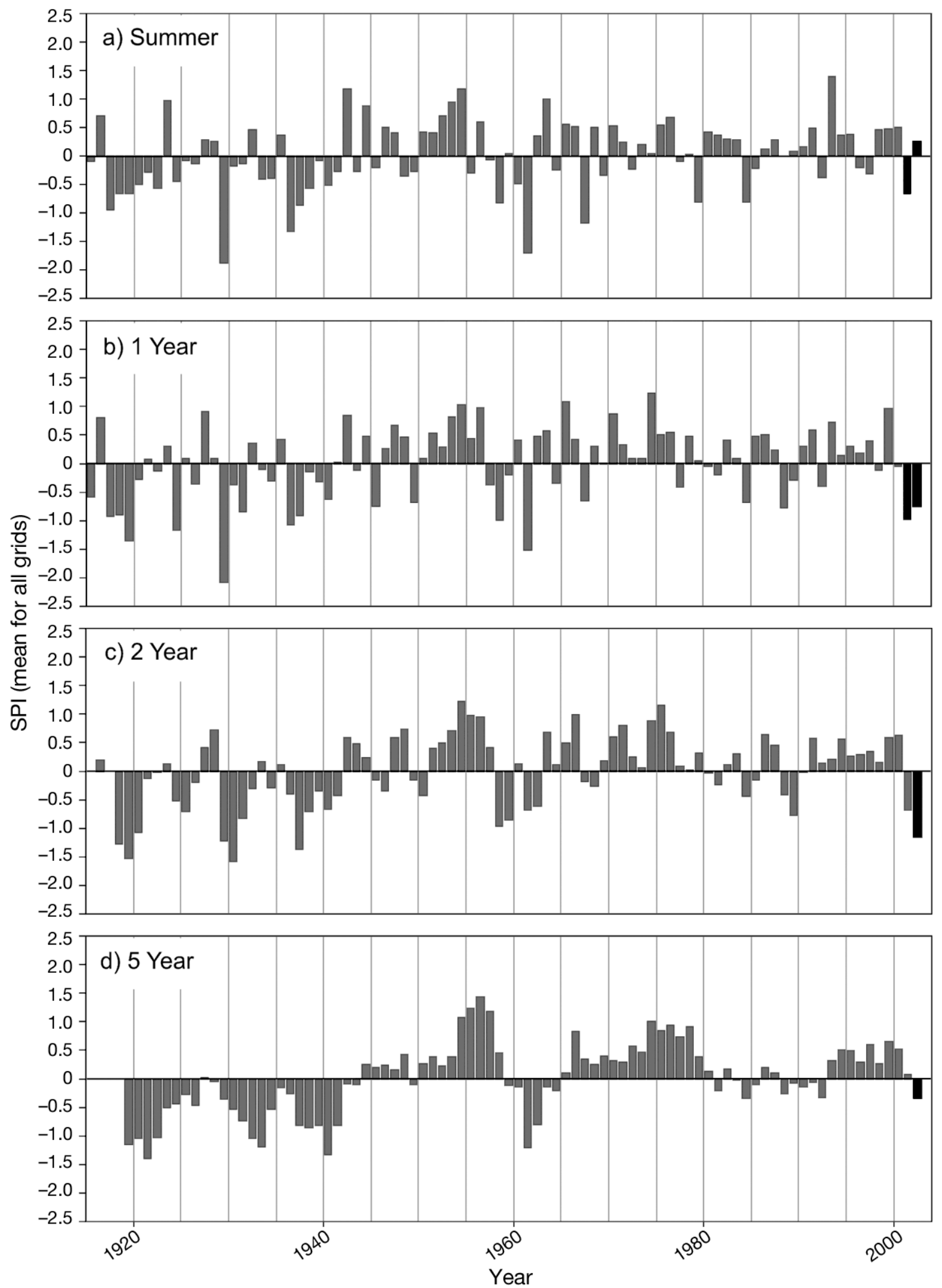

Fig. 5. Standardized Precipitation Index (SPI). Average values for all grids during 1915-2002. Values for the 2001/2002 drought are in black 


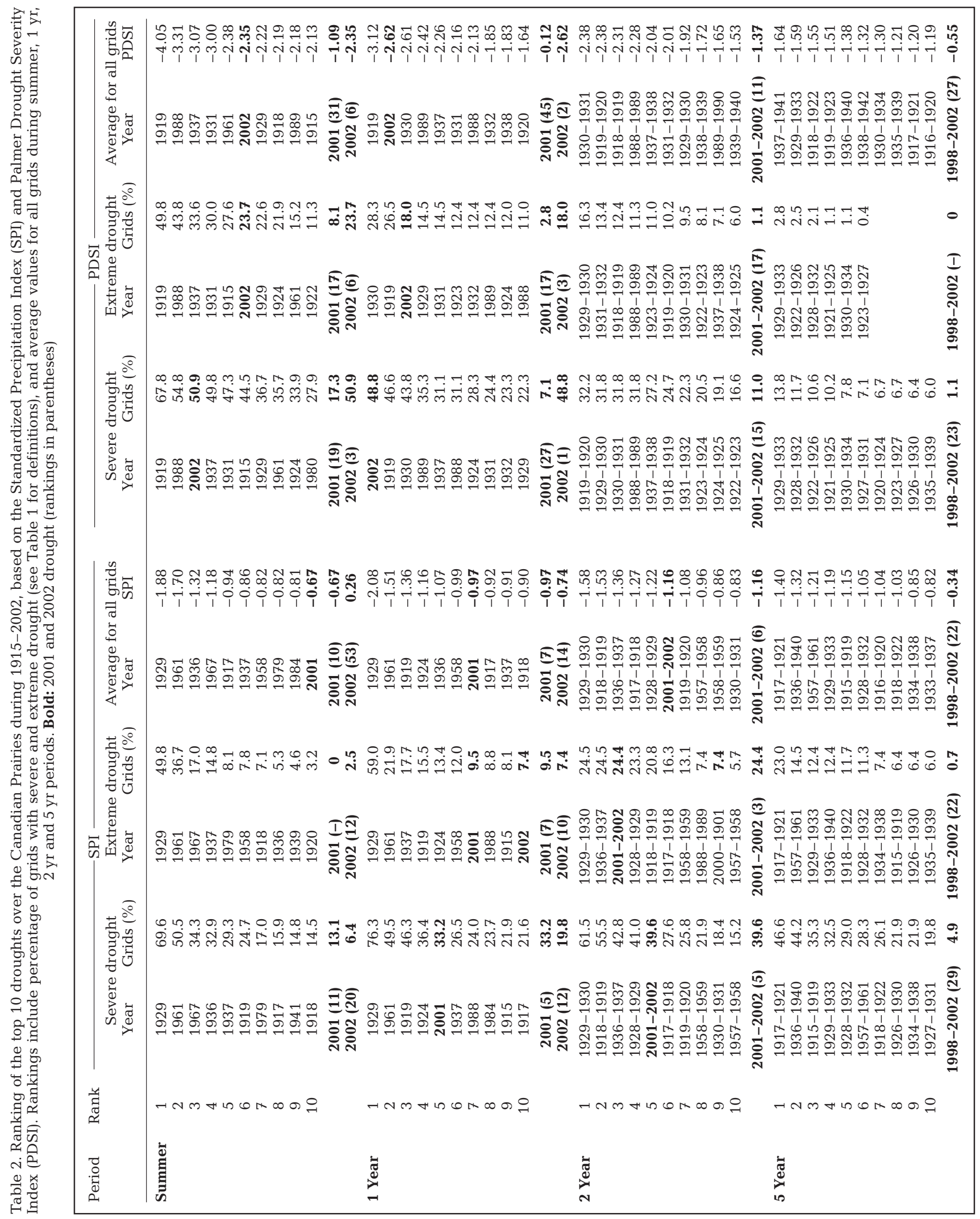



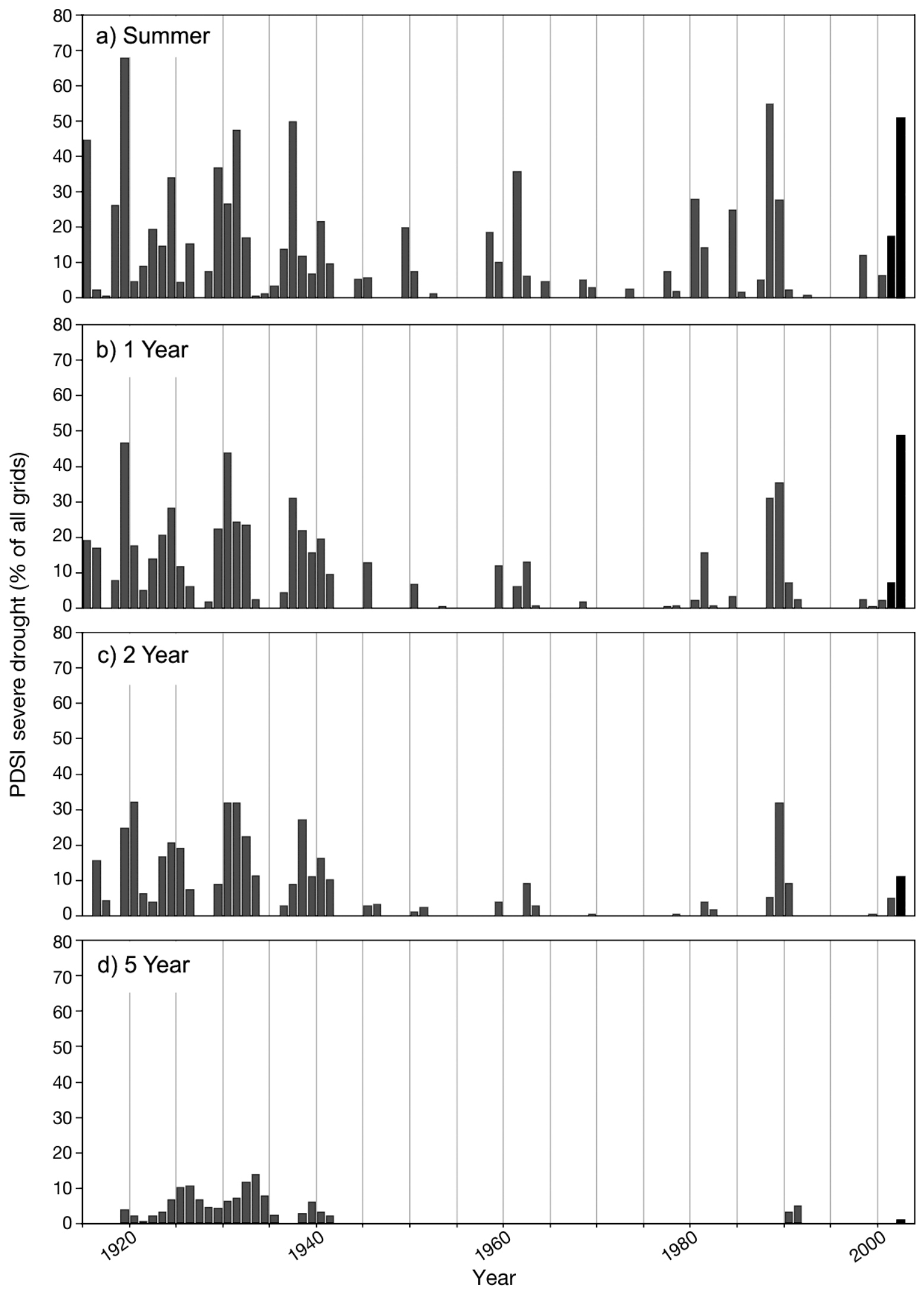

Fig. 6. Palmer Drought Severity Index (PDSI). Same type of values as in Fig. 4, for PDSI $\leq-3.0$ 

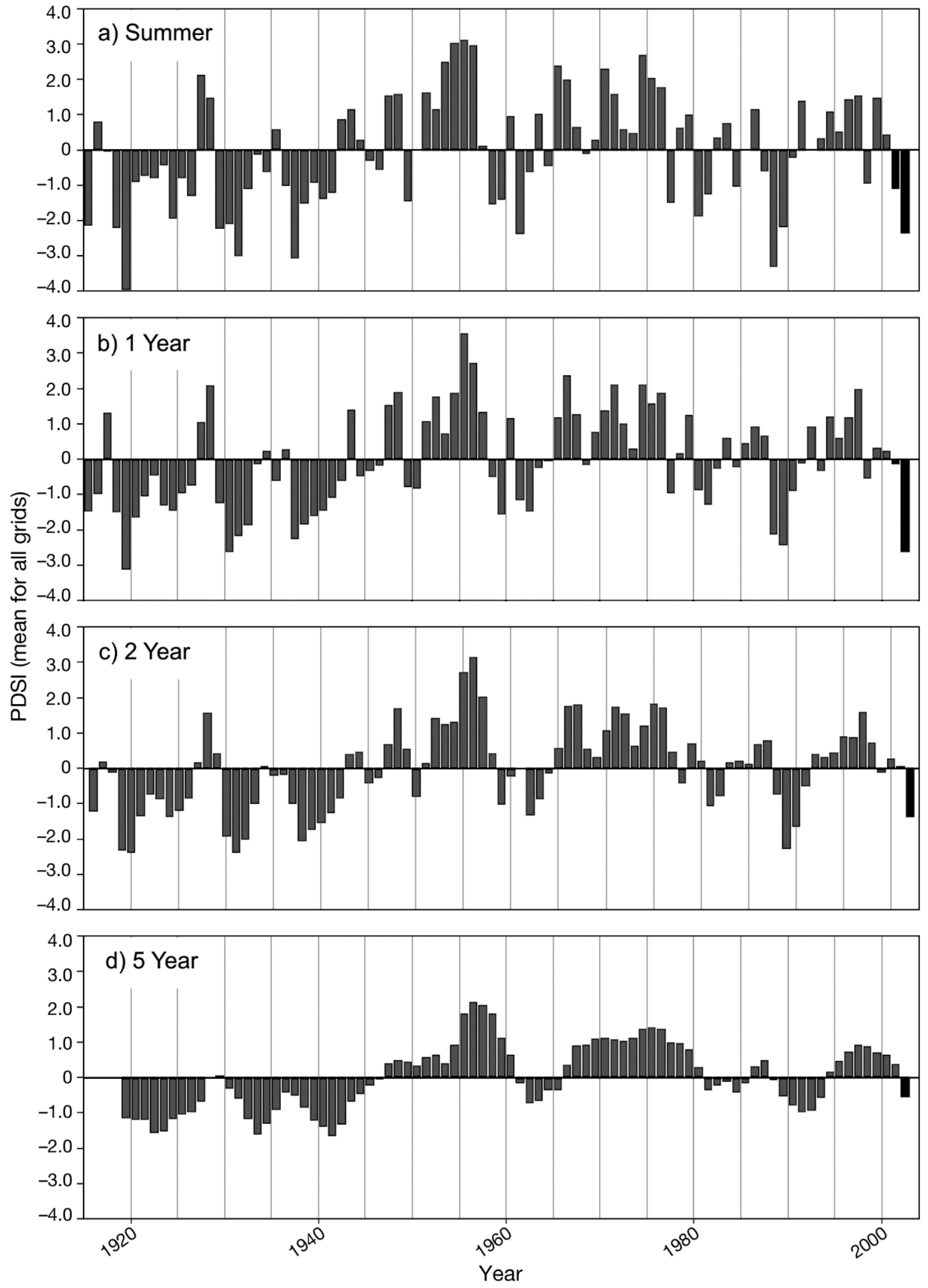

Fig. 7. Palmer Drought Severity Index (PDSI). Same type of values as in Fig. 5 


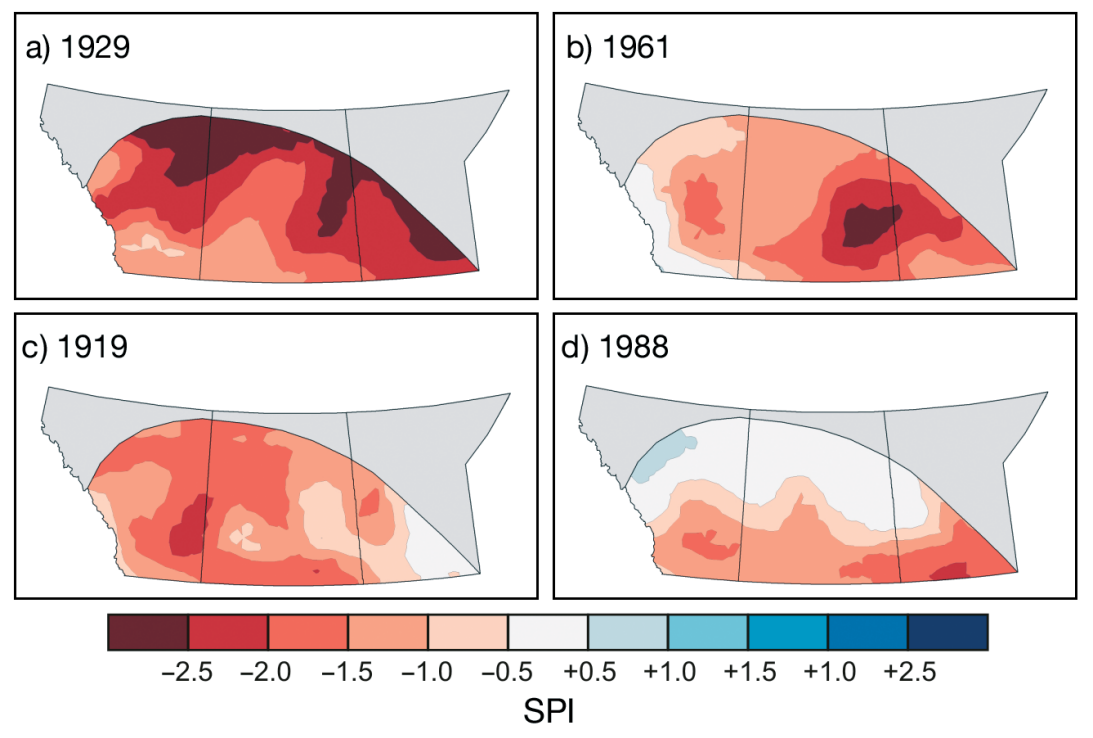

Fig. 8. Standardized Precipitation Index (SPI) for agricultural years with severe drought

Prairies with the core of the drought centred in eastern Saskatchewan and western Manitoba. Drier than normal conditions encompassed much of the Prairies in 1919; they were not as severe as 1929, however, and the 1919 drought was shifted southward near the Alberta/Saskatchewan border. During 1988, the most serious drought conditions occurred in the southern Prairies and in particular, southern Manitoba. In comparison, the 1 yr SPI values for 2001 and 2002 (Fig. 2c,d) show that the driest conditions associated with this drought were centred over Alberta and western Saskatchewan. In addition, the spatial extent and severity of the 2001/2002 drought was less, compared to the drought years of 1929, 1961 and 1919 (consistent with Table 2).

PDSI values during the extreme drought years of 1919, 1930, 1937, and 1989 are provided in Fig. 9. These maps, along with those in Fig. 3, show once again that individual droughts have considerable spatial variability within the Prairie region. They also reveal relationships between the SPI and PDSI indices used to analyze drought in this study. The spatial drought patterns of the PDSI in 1930 and 1989 (Fig. 9b,d) are similar to the SPI patterns for 1929 and 1988 (Figs. 8a,d). Although 1930 and 1989 were also associated with below normal precipitation over the Prairies (not shown), these similarities indicate the long persistence associated with PDSI values. The 1919 PDSI (Fig. 9a) shows severe to exceptional drought conditions over the west-central Prairies. The most severe drought is shifted north in comparison to the SPI (cf. Fig. 8c). The year 1937 has also been identified as a drought year on the Prairies by Maybank et al. (1995), and this is clearly evident in Fig. 9c, where severe drought is shown over eastern Alberta and western Saskatchewan. This pattern reflects the dry conditions over this region during 1936 and 1937 (not shown).

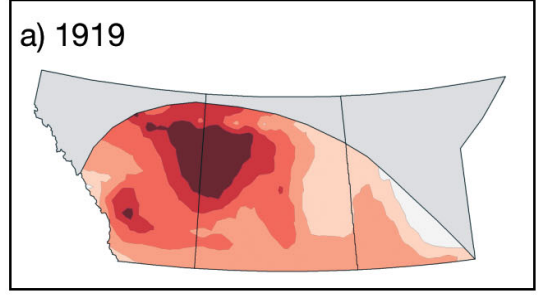

b) 1930
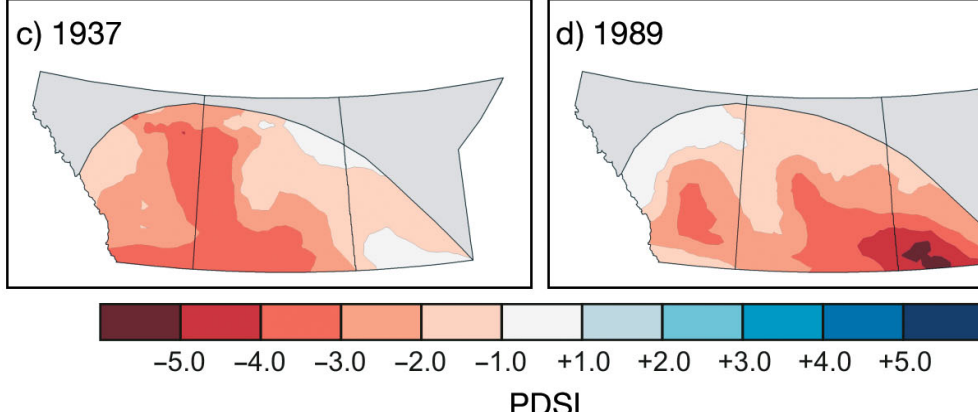

PDSI

Fig. 9. Palmer Drought Severity Index (PDSI) for agricultural years with severe drought

\section{SUMMARY AND DISCUSSION}

This study examined the $2001 / 2002$ Canadian Prairie drought in the context of historical drought occurrences. The SPI and PDSI as drought indicators revealed that the worst and most prolonged Prairie-wide droughts during the instrumental record (1915-2002) have occurred in the early part of the 20th century (1915 through the 1930s), with individual drought years also in 1961 and 1988. The spatial extent and severity of the 2001/2002 drought ranked below the early episodes, however, for most periods analyzed it was one of the top 10 worst droughts during the instrumental period. More importantly, it followed a prolonged ab- 
sence of dry years, which likely contributed to the severe impacts of the 2001/2002 drought. In terms of SPI, 2001 and 2002 were the worst $1 \mathrm{yr}$ droughts since 1961, and the worst 2 yr drought since 1929-1930; for PDSI, 2002 was one of the worst $1 \mathrm{yr}$ droughts on record (Table 2).

These findings were based on analyses over the entire southern Canadian Prairies, and as such, provided comparisons of larger-scale Prairie droughts. As shown in Figs. 2, 3, 8 \& 9, past Prairie droughts have shown considerable spatial variability, with the 2001/ 2002 episode being concentrated in the west-central Prairie region in 2001 and migrating northward in 2002. Examination of individual climate stations used in this analysis (not shown) revealed that for certain locations, 2001 and 2002 did rank as the worst or near worst drought during the study period. For example, the 2001 and 2001-2002 SPI values were the lowest on record for Prince Albert and Saskatoon, Saskatchewan, and the second lowest on record for Edmonton and Lacombe, Alberta. In terms of PDSI, Saskatoon had a record value of -5.47 for the 2002 agricultural year (previous record was -4.67 in 1988), while Prince Albert, and Banff, Alberta, had the second lowest value in the $88 \mathrm{yr}$ period. The 2001-2002 PDSI value was also record-setting for Medicine Hat and Banff, Alberta.

Due to data restrictions, the historical analysis of droughts was confined to the southern Prairie Provinces. Even so, there were station gaps over the study area (see Fig. 1), and these may have influenced the spatially averaged historical comparisons. The incorporation of gridded monthly temperature and precipitation datasets to calculate PDSI and SPI values over the Canadian Prairies was considered, but it was felt that the methodology used in this analysis provided a more consistent approach, due to the fact that the number of stations used for each time period remains the same. With most gridded products, stations incorporated in the gridding procedure vary, depending on station availability for the period in question. This may, for example, bias results in the latter part of the 20th century, due to the higher density of stations in more recent years. One disadvantage, however, is that the spatial coverage is compromised over certain regions of the study area. Nonetheless, it is still likely that on larger scales the worst droughts on record occurred in the early part of the 20th century.

The SPI and PDSI both reveal similar overall findings, in that the worst droughts have occurred in the early 20th century. However, the ranking of individual drought periods often differs between the indices (Table 2), likely due to the PDSI having a long-term memory of previous moisture conditions and thus being more suited to assess longer-term hydrologic drought. The SPI on the other hand, is reflective of meteorological conditions during the current period of interest. As a result, the most serious PDSI droughts tend to follow those associated with the SPI (e.g. 1929 and 1930; Figs. 8a \& 9a). This is also why for PDSI, 2002 was more severe than 2001 (Fig. 3). Several investigations have evaluated numerous drought indices on various spatial and temporal scales, and have concluded that with respect to meteorological drought, the SPI is the preferred drought indicator, since it is easy to interpret and can be applied universally to any location at various temporal scales (e.g. Guttman 1998, Keyantash \& Dracup 2002). Although a lack of precipitation is the main meteorological driver of severe drought conditions, droughts are often enhanced by anomalously high temperatures that increase evaporation. As a result, indices that incorporate temperature (such as the PDSI) may be better suited for assessing droughts that have been influenced by anomalously high temperatures. In addition, since all Global Climate Models (GCMs) project temperature increases over land regions of the Northern Hemisphere, indices that incorporate temperature may be better suited for assessing climate-change impacts on future droughts.

A preliminary analysis of climate change impacts on future droughts over the Prairies (not shown) indicates that the spatial extent and severity of future droughts based on the SPI will not be significantly altered. However, PDSI results differ greatly, in that future droughts are projected to dramatically increase in both spatial extent and severity. These differences are attributed to the PDSI's inclusion of temperature in its calculation. All GCM scenarios project considerable increases to temperature and, in general, small increases to precipitation over the Canadian Prairies (not shown). The higher temperatures translate into greater evaporation and more severe droughts. Since the SPI only takes into account precipitation, droughts using this index are not projected to become more severe in the future. However, further research is required to better quantify future drought occurrence over various regions of Canada. This should include the use of a drought index that accounts for evaporation, but is not greatly influenced by a substantial lag in previous moisture conditions.

In conclusion, this study has analyzed the 2001/2002 Canadian Prairie drought in the context of past droughts over the region. Results revealed that although these droughts were not as severe as those early in the 20th century, they occurred following a prolonged lack of severe droughts. Future research requires more in-depth analyses of both past and potential future drought occurrences at a variety of spatial and temporal scales, including a thorough evaluation of several drought indices. This study is an initial step toward the better understanding of both past and future drought occurrence over interior regions of North America. 
Acknowledgements. Funding for this research was provided in part by the Government of Canadas Climate Change Impacts and Adaptation Programme. We also thank the 2 anonymous reviewers for their useful suggestions toward an improved version of the manuscript.

\section{LITERATURE CITED}

AES (Atmospheric Environment Service) (1986) An applied climatology of drought in the Canadian Prairie Provinces. AES Drought Study Group Rep No 86-4, Canadian Climate Centre, Downsview, ON

Arnell N, Chunzhen L, Compagnucci R, da Cunha L and 5 others (2001) Hydrology and water resources. In: McCarthy JJ, Canziani OF, Leary NA, Dokken DJ, White KS (eds) Change 2001, impacts, adaptation and vulnerability. Contribution of Working Group II to the third Assessment Report of the IPCC, Cambridge University Press, Cambridge, $\mathrm{p}$ 191-233

Bonsal BR, Wheaton EE (2005) Atmospheric circulation comparisons between the 2001 and 2002 and the 1961 and 1988 Canadian Prairie droughts. Atmos Ocean 43:163-172

Chipanshi AC, Findlater KM, Hadwen T, O'Brien EG (2006) Analysis of consecutive droughts on the Canadian Prairies. Clim Res 30:175-187

Guttman NB (1998) Comparing the Palmer Drought Index and the Standardized Precipitation Index. J Am Water Res Assoc 34:113-121

Guttman NB (1999) Accepting the standardized precipitation index: a calculation algorithm. J Am Water Res Assoc 35: 311-322

Heim HR Jr (2002) A review of twentieth century drought indices used in the United States. Bull Am Meteorol Soc 83:1149-1165

Keyantash J, Dracup JA (2002) The quantification of drought: an evaluation of drought indices. Bull Am Meteorol Soc 83:1167-1180

Maybank J, Bonsal BR, Jones K, Lawford RG, O'Brien EG, Ripley EA, Wheaton E (1995) Drought as a natural disaster. Atmos Ocean 33:195-222

McKee TB, Doeskin NJ, Kleist J (1993) The relationship of

Editorial responsibility: Daniel Scott,

Waterloo, Ontario, Canada drought frequency and duration to time scales. Preprints, Proc 8th Conf Appl Climatol, January 17-22, 1993, Am Meteorol Soc, Anaheim, CA, p 179-184

Mekis E, Hogg WD (1999) Rehabilitation and analysis of Canadian daily precipitation time series. Atmos Ocean 39: 53-85

Nkemdirim L, Weber L (1999) Comparison between the droughts of the 1930s and the 1980s in the southern Prairies of Canada. J. Clim 12:2434-2450

O'Brien EG (1994) Drought in Canada. In: The Canadian National Committee for the International Decade for Natural Disaster Reduction national report, prepared for the IDNDR Mid-Term Review and the 1994 World Conference on National Disaster Reduction, Yokohama, Japan, 23-27 May 1994. Royal Society of Canada, Canadian Academy of Engineering

Palmer WC (1965) Meteorological drought. Res Pap No 45, Weather Bureau, Washington, DC

Palmer WC (1968) Keeping track of crop moisture conditions, nationwide: the new Crop Moisture Index. Weatherwise 21:156-161

Phillips DW (1990) The climates of Canada. Environment Canada, Ottawa

Sauchyn DJ, Skinner WR (2001) A proxy record of drought severity for the southwestern Canadian Plains. Can Water Res 26:253-272

Shafer BA, Dezman LE (1982) Development of a Surface Water Supply Index (SWSI) to assess the severity of drought conditions in snowpack runoff areas. Proc Western Snow Conf, Colorado State University, Fort Collins, $\mathrm{CO}, \mathrm{p}$ 164-175

Vincent LA (1998) A technique for the identification of inhomogeneities in Canadian temperature series. J Clim 11: 1094-1104

Vincent LA, Gullet DW (1999) Creation of historical and homogeneous temperature datasets for climate change analyses in Canada. Int J Climatol 19:1375-1388

Wheaton, E, Wittrock V, Kulshreshtha S, Koshida G, Grant C, Chipanshi A, Bonsal BR (2005) Lessons learned from the drought years of 2001 and 2002: synthesis report. Agriculture and Agri-Food Canada, Saskatchewan Research Council Publ No. 11602-46E03, Saskatoon

Submitted: September 25, 2006; Accepted: February 22, 2007 Proofs received from author(s): March 30, 2007 